\title{
Influencia de los guías de turismo en la calidad del servicio en el Museo del Convento de San Francisco
}

\author{
Influence of tour guides on the quality of service at the San \\ Francisco Convent Museum
}

\author{
Florisa García Chumioque ${ }^{\circledR}$, (D) Pedro Pizarro Ramos
}

Universidad Le Cordon Bleu. Lima, Perú

Recibido: $17 / 04 / 2020 \quad$ Revisado: 20/06/2020 Aceptado: 11/11/2020 Publicado: $16 / 12 / 2020$

\section{RESUMEN:}

Cualquier tipo de servicio sin dosis de calidad es complicado que pueda cubrir o superar las expectativas del cliente o visitante, esta clase de situaciones traen como resultado que los clientes o visitantes no regresen ni recomienden el servicio, significando todo esto deficiencias económicas producto de un mal servicio.La presente investigación tiene como objetivo "Identificar qué tipo de relación e influencia existe entre el guiado turístico y la calidad del servicio en el museo del Convento San Francisco". La muestra estuvo conformada por 384 visitantes del Museo, la misma fue caracterizada por género, grupo etario, el instrumento estuvo enfocado en conocer el nivel del entusiasmo del guía de turismo, el uso de algún equipamiento tecnológico en el servicio de guiado, el nivel de atención a los visitantes del museo, la ética y la moral del guía de turismo para hacer cumplir las normas pertinentes durante la visita in situ para salvaguardar la integridad de las colecciones. Los resultados obtenidos determinan que se debe mejorar los procesos que se vienen utilizando durante el desarrollo del servicio, se identificaron dos segmentos de visitantes, uno de ellos les interesa conocer del Museo solo los aspectos básicos y elementales y el otro segmento está muy interesados en los aspectos técnicos-artísticos de las colecciones. Para generar experiencias agradables en cada uno de estos segmentos es importante elaborar un manual de procedimientos administrativos, asimismo se debe elaborar un manual para el Guía de turismo del Museo del Convento de San Francisco. Palabras clave: Museo, Convento, San Francisco, Catacumbas, Satisfacción de Cliente, Gestión de Servicio.

\begin{abstract}
:
Any type of service without a dose of quality is difficult to meet or exceed the expectations of the customer or visitor, this kind of situation results in customers or visitors not returning or recommending the service, all this signifying economic deficiencies as a result of a bad service. The present research aims to "Identify what type of relationship and influence exists between tourist guidance and the quality of service in the San Francisco Convent museum".

The sample consisted of 384 visitors to the Museum, it was characterized by gender, age


group, the instrument was focused on knowing the level of enthusiasm of the tour guide, the use of some technological equipment in the guide service, the level of attention to museum visitors, ethics and morals of the tour guide to enforce relevant regulations during the on-site visit to safeguard the integrity of the collections. The results obtained determine that the processes that have been used during the development of the service must be improved, two segments of visitors were identified, one of them is interested in knowing about the Museum only the basic and elementary aspects and the other segment is very interested in the technical-artistic aspects of the collections. In order to generate pleasant experiences in each of these segments, it is important to develop a manual of administrative procedures, as well as a manual for the Tourism Guide of the San Francisco Convent Museum. Keywords: Museum, Convent, San Francisco, Catacombs, Customer Satisfaction, Service Management.

\section{INTRODUCCIÓN}

Para el Consejo Internacional de Museos (ICOM), el museo es una institución permanente, sin fines de lucro, al servicio de la sociedad y de su desarrollo, abierta al público y que efectúa investigaciones sobre testimonios materiales de la humanidad y de su medio ambiente, adquiridos, conservados, comunicados $\mathrm{y}$, sobre todo, expuestos para fines de estudio, de educación y deleite. La definición actual, que solo ha experimentado pequeños ajustes en las últimas décadas, no refleja ni expresa adecuadamente las complejidades del siglo XXI y las responsabilidades y compromisos actuales de los museos, ni sus desafíos y visiones para el futuro.

La tendencia casi imprescindible de los museos en general y especialmente del museo del Convento de San Francisco, de centrarse en los visitantes provoca la necesidad de mejorar los servicios dirigidos a estos en los museos. Los visitantes están acostumbrados a recibir servicios de calidad en todo lugar de ocio y esperan lo mismo de los museos. El aumento en la competencia por obtener un espacio de entretenimiento requiere que los museos evalúen cómo tratan y atienden a sus visitantes si es que desean que vuelvan.
El público visita los museos para entretenerse y aprender, para pasar un rato de ocio agradable solos o en compañía, pero las malas instalaciones o personal antipático transforman lo que podrían ser una buena experiencia en un mal trato, algo que afecta al aprendizaje y al disfrute del tiempo libre. Según (Hein, 2012) los museos son lugares importantes para el aprendizaje. Sin embargo, podemos correr el riesgo que la experiencia del museo en su conjunto pueda ser elusiva y vaga.

La iglesia y el convento de San Francisco el Grande, enmarcados por las iglesias de la Soledad y el Milagro y la bella plazuela del mismo nombre forman el más notable y mejor conservado conjunto monumental de la colonia en Lima. (Gran Enciclopedia del Perú, 1998)

Y es que San Francisco - irreparable y ciegamente mutilado para abrir la avenida Abancay, ya que actualmente ocupa una tercera parte de su área original - no es solo el templo, ni solo el convento o los tesoros que guarda, ni solo la belleza estética o el evocado y apacible ambiente de su plazuela. Es todo eso en conjunto y más aún, porque San Francisco, cuya construcción se inició en el tercer cuarto del siglo XVI, es el triunfo del barroco claramente defi 
nido en escuelas regionales y de esa arquitectura plenamente expresiva que surge en Lima. La consagración tuvo lugar el 3 de octubre de 1673, luego de casi un siglo de iniciada su construcción, y estuvo a cargo del obispo Manuel Mollinedo y Angulo. El maestro lusitano Constantino de Vasconcellos, su constructor, no alcanzo a ver concluida su obra. El almohadillado, en el que se alternan en líneas horizontales fajas y sillares, es una de las características saltantes de la arquitectura de San Francisco y acentúa con realce el claroscuro, que es una de las notas propias y originales del barroco en el Perú y especialmente en Lima.

Además de la belleza de su arquitectura, el interior de San Francisco es un valioso museo por la calidad de sus obras de arte, de las que es atracción especial la famosa colección de lienzos de los apóstoles, atribuidos al pintor español Francisco de Zurbarán; además de otras valiosas colecciones pictóricas. En las galerías subterráneas se encuentran las impresionantes catacumbas, descubiertas en 1951, donde se presume que se hallan sepultados más de 80 mil cuerpos. En 1995, luego de cinco años de trabajos de reconstrucción, se reabrió al público la Sacristía, afectada por el terremoto de 1974. La puesta en valor de las estructuras e imágenes se realizó en base a una investigación histórica y arqueológica, con el aporte financiero de la Agencia Española de Cooperación Internacional (AECI). (Gran Enciclopedia del Perú, 1998).

El Museo de San Francisco de Lima es uno de los centros históricos, artísticos, culturales, y religiosos más importantes del País, uno de los museos más visitados de la ciudad, por ello uno de los más importantes e influyentes. Desde la antigüedad el propósito de los templos y conventos fue atender la necesidad religiosa de las personas, sin embargo, esta concepción ha cambiado. Pues al poseer estos recintos un legado artístico de incalculable valor ha hecho que los conventos e iglesias abran sus puertas al público para mostrar y exhibir aquellas obras de arte que han acercado al hombre a Dios desde que el cristianismo llegó a nuestras tierras. Es así que la curiosidad de los franciscanos por dar a conocer lo que guardaban en el convento hace que en la década de los 60 se empiece a propagar la idea de mostrar las obras de arte que tiene la iglesia de San Francisco armándose salas de exhibición. Para la década de los 70' el claustro del convento empieza a funcionar como un museo de sitio donde se muestran las diferentes obras de arte y se empiezan los primeros trabajos en las famosas catacumbas que años más tarde se convertirían en un referente y el producto emblema del museo. (Farfán, 2015).

El objetivo del trabajo para la presente investigación fue Identificar qué tipo de relación e influencia existe entre el guiado turístico y la calidad del servicio en el museo del Convento de San Francisco. Actualmente el Museo de San Francisco de Lima ejerce sus actividades como un museo que brinda servicios turísticos, ofrece oportunidades de mostrar exposiciones temporales a nuevos artistas y además del compromiso con la responsabilidad social. (Farfán, 2015), en este sentido, los museos no son ajenos a esta realidad y más aún en nuestro país donde éstos representan un atractivo importante para los visitantes extranjeros y nacionales. Los visitantes extranjeros llegan en busca de nuevas experiencias, con altas expectativas y altos estándares de satisfacción; mientras que, los visitantes nacionales están enfocados en recibir un servicio que supere sus expectativas para sentirse satisfechos. Por otro lado, los 
trabajadores (clientes internos) también tienen expectativas y niveles de satisfacción, es decir, si ellos no están satisfechos con el trabajo que realizan es poco probable que brinden un servicio de calidad y, por ende, es muy probable que la organización no alcance los niveles óptimos de satisfacción en los clientes.

\section{MATERIALES Y MÉTODOS}

El tipo de estudio es descriptivo es un tipo de metodología a aplicar para deducir un bien o circunstancia que se esté presentando; se aplica describiendo todas sus dimensiones. El diseño de la investigación es cuantitativa y descriptiva. La Población estuvo comprendida por los visitantes del Museo del Convento de San Francisco. La Muestra estuvo conformada por 384 visitantes del Museo del Convento de San Francisco. Las técnicas de recolección de datos fueron las encuestas a los visitantes del Museo del Convento de San Francisco.

Asimismo, logramos identificar las características de la muestra en función al género y grupo etario, tal como se muestra a continuación:

Tabla 1. Género de los visitantes del Museo del Convento de San Francisco.

\begin{tabular}{ccc}
\hline Género & Cantidad & Porcentaje \\
\hline Masculino & 224 & $58 \%$ \\
Femenino & 160 & $42 \%$ \\
\hline \hline Total & 384 & $100 \%$ \\
\hline
\end{tabular}

Fuente. Elaboración propia

$\mathrm{Al}$ respecto esta registra que el 58\% de los encuestados manifestaron pertenecer al género masculino, los mismos que estuvieron conformados por 224 participantes, mientras que el $42 \%$ de las encuestadas manifestaron per- tenecer al género femenino, las mismas que estuvieron conformadas por 160 participantes.

Tabla 2. Edad de los visitantes del Museo del Convento de San Francisco.

\begin{tabular}{ccc}
\hline Edad & Cantidad & Porcentaje \\
\hline $15-20$ & 28 & $7 \%$ \\
$20-25$ & 44 & $11 \%$ \\
$25-30$ & 83 & $22 \%$ \\
$30-35$ & 74 & $19 \%$ \\
$35-40$ & 71 & $18 \%$ \\
Mas de 40 & 84 & $22 \%$ \\
\hline \hline Total & 384 & $100 \%$ \\
\hline
\end{tabular}

Fuente. Elaboración propia

$\mathrm{Al}$ respecto esta registra que los grupos etarios estuvieron conformados de la siguientemanera:

- $\quad$ El $7 \%$, los mismos que están conformados por 28 participantes oscilan entre los " 15 20 " años de edad. El $11 \%$, los mismos que están conformados por 44 participantes oscilan entre los " 20 - 25 " años de edad. El $22 \%$, los mismos que están conformados por 83 participantes oscilan entre los " 25 30 " años de edad. El $19 \%$, los mismos que están conformados por 74 participantes oscilan entre los “ 30 - 35" años de edad. El $18 \%$, los mismos que están conformados por 71 participantes oscilan entre los " 35 40 " años de edad. $22 \%$, los mismos que están conformados por 84 participantes figuran como "más de 40 años de edad".

\section{RESULTADOS Y DISCUSIÓN}

La Muestra estuvo conformada por 384 visitantes que arribaron al Museo del Convento de San Francisco, en más de una oportunidad, quienes a su vez se mostraron dispues- 
tos a colaborar brindando información de su experiencia. En cuanto a los encuestados, se hicieron inicialmente las aclaraciones respecto a la naturaleza del trabajo de investigación y fueron pocas las personas que se negaron a ser encuestadas, a lo cual se respetó su decisión. Se utilizaron cuatro fines de semana, para aplicar las encuestas diseñadas. Se eligió los fines de semana, debido a que estos días suelen ser los más frecuentados. En varias ocasiones realizamos las gestiones pertinentes para sostener una entrevista con "Fray Ernesto Chambi Cruz", director del Museo, pero en coordinación siempre nos manifestaron que no podía atendernos, debido a que se encontraba de viaje por el extranjero.

Tabla 3. Trabajo con esmero de parte de los Guías de Turismo.

\begin{tabular}{ccc}
\hline Realiza un trabajo esmerado & Cantidad & Porcentaje \\
\hline Siempre & 31 & $8 \%$ \\
A veces & 270 & $70 \%$ \\
Nunca & 83 & $22 \%$ \\
\hline \hline Total & 384 & $100 \%$ \\
\hline
\end{tabular}

Fuente. Elaboración propia

Cuando se realizó esta interrogante a los visitantes encuestados, pretendimos averiguar de parte de ellos, que sintió respecto al trabajo desarrollado por parte del Guía de Turismo. Por esta razón se formuló la pregunta ¿Considera usted que los Guías de Turismo del Museo del Convento de San Francisco realizan un trabajo esmerado?, cuando consideramos la palabra "esmerado", pretendimos averiguar, si el visitante percibió que el Guía de Turismo realizó su trabajo con mucha dedicación, buscando siempre minimizar la presencia de errores. Para lo cual el $8 \%$ de los encuestados manifestó "siempre", el $70 \%$ "a veces" y el $22 \%$ "nunca".
Tabla 4. Equipamiento tecnológico.

\begin{tabular}{ccc}
\hline Demuestra ética profesional durante su trabajo & Cantidad & Porcentaje \\
\hline Siempre & 229 & $60 \%$ \\
A veces & 119 & $31 \%$ \\
Nunca & 36 & $9 \%$ \\
\hline \hline Total & 384 & $100 \%$ \\
\hline
\end{tabular}

Fuente. Elaboración propia

El Guía de Turismo para un mejor desempeño de su trabajo profesional suele usar uno o varios dispositivos tecnológicos. En el caso particular a este trabajo de investigación, se pretendió averiguar, si el Guía de Turismo hizo uso de algún equipamiento tecnológico para superar las barreras de la comunicación que trae consigo algunos ambientes del museo en materia de acústica, espacio reducido, el bajo nivel de timbre de voz de parte de los Guías de Turismo o las debilidades auditivas que suelen poseer algunos visitantes. Definitivamente el ambiente que ofreció algunas barreras para la comunicación fue las Catacumbas, debido a su espacio reducido, lo cual dificultó que el grupo de visitantes se ubique de la manera adecuada para recepcionar satisfactoriamente el mensaje emitido por el Guía de Turismo. Tomando en cuenta toda esta realidad, el $100 \%$ de los visitantes encuestados manifestaron que "nunca" vieron a los Guías de Turismo usar algún equipamiento tecnológico para superar las barreras de la comunicación.

Tabla 5. Atención a los requerimientos de los visitantes.

\begin{tabular}{ccc}
\hline Atención frente a los requerimientos de los visitantes & Cantidad & Porcentaje \\
\hline Siempre & 52 & $14 \%$ \\
A veces & 189 & $49 \%$ \\
Nunca & 143 & $37 \%$ \\
\hline \hline Total & 384 & $100 \%$ \\
\hline
\end{tabular}

Fuente. Elaboración propia 
El requerimiento solicitado por el visitante, que capturó nuestra mayor atención, fue en la Sala de Espera, mientras el grupo esperó su turno para iniciar el recorrido por las instalaciones del museo. Una visitante perteneciente a este grupo solicitó hacer uso de los servicios higiénicos y nuestra impresión fue tal, cuando la persona que controló el ingreso, manifestó que, para hacer uso de los servicios higiénicos, el grupo tenía que estar en pleno recorrido por las instalaciones del museo. Es probable que existan otras clases de requerimientos solicitados por los visitantes que si son atendidos con la debida prudencia y otros que merecen un especial cuidado para mantener de manera muy grata la imagen de este museo. Toda esta situación nos llevó a formular esta interrogante, a la cual el visitante respondió que el $14 \%$ manifestó que "siempre" el Guía de turismo atendió a sus requerimientos, el $49 \%$ manifestó que "a veces" y el 37 \% manifestó que "nunca".

Tabla 6. Ética profesional frente a los visitantes.

\begin{tabular}{ccc}
\hline Demuestra ética profesional durante su trabajo & Cantidad & Porcentaje \\
\hline Siempre & 229 & $60 \%$ \\
A veces & 119 & $31 \%$ \\
Nunca & 36 & $9 \%$ \\
\hline \hline Total & 384 & $100 \%$ \\
\hline
\end{tabular}

Fuente. Elaboración propia

De todas las ocasiones que visitamos este museo como parte del trabajo de investigación, siempre se pudo constatar que el Guía de Turismo fue muy estricto respecto al cumplimiento de las normas internas para el visitante, a excepción de la última visita que se realizó, hubo algo que nos llamó la atención durante este recorrido. El Guía de Turismo que estuvo a cargo de la conducción de nues- tro grupo, mientras recorríamos una de las salas de este museo, nos manifestó que, si deseamos, podíamos hacer alguna toma fotográfica, pero debemos tener mucho cuidado que no nos encuentren infragante otro Guía de Turismo o algún vigía, para así evitar alguna llamada de atención. El conocimiento de toda esta realidad nos llevó a incluir esta interrogante en la encuesta dirigida al visitante, a lo cual manifestó que el $60 \%$ de los visitantes "siempre" observaron a los Guías de Turismo demostrar ética profesional, el $31 \%$ manifestó que "a veces" y el $9 \%$ manifestó que "nunca".

Tabla 7. Atención personalizada.

\begin{tabular}{ccc}
\hline Atención personalizada & Cantidad & Porcentaje \\
\hline Siempre & 0 & $0 \%$ \\
A veces & 0 & $0 \%$ \\
Nunca & 384 & $100 \%$ \\
\hline \hline Total & 384 & $100 \%$ \\
\hline
\end{tabular}

Fuente. Elaboración propia

El número de visitante que se asignó a cada Guía de Turismo fue fluctuante según la temporada del año. Durante la visita realizadas al museo como parte del proceso de investigación se verificó que cada Guía de Turismo ingresó con 15 o 20 visitantes y en otra oportunidad el Guía de Turismo estuvo a cargo de 30 o 40 visitantes, en definitiva la cantidad de visitantes por cada Guía de Turismo debe estar en función a la capacidad de que estos, puedan ser atendidos de manera personalizada por cada Guía de Turismo, en otro momento mientras hacíamos el recorrido por las Catacumbas, el grupo de visitantes fue tan extenso para un solo Guía de Turismo y como consecuencia se presentaron muchas dificultades para escuchar el mensaje, en otra ocasión una visitante tuvo un problema de claustrofobia y 
fue asistida por dos visitantes que se encontraban al final del grupo. El Guía de Turismo no pudo percatarse de esta situación debido al número excesivo de visitantes que le asignó la administración. Tomando en cuenta tal situación, se formuló esta interrogante a los visitantes, a lo cual ellos respondieron que el 100 \% "nunca” recibió atención personalizada.

Como parte del resultado que se logró obtener de este trabajo de investigación, el $70 \%$ de la muestra aseguró que los Guías de Turismo del Museo del Convento de San Francisco "a veces" desarrolló su trabajo con mucha dedicación, buscando en todo momento minimizar la presencia de errores, mientras que el $8 \%$ aseguró que "siempre" y el $22 \%$ que "nunca". Si analizamos estos resultados, se cercioró que el mayor volumen de visitantes calificó que "a veces" los Guías de Turismo de este museo desarrolló su trabajo con esmero, definitivamente el resultado no es muy alentador debido a que solo el $8 \%$ consideró que "siempre" hay esmero por parte del Guía de Turismo. Entonces está claro que este museo debió tomar algunas medidas correctivas al corto plazo para que el mayor volumen porcentual de las cifras se incline a favor de la calificación "siempre". Algunos aspectos que se han de considerar para que en una próxima evaluación, los visitantes perciban que realmente hay un trabajo esmerado, lo manifiesta (Farfán, 2015) "los visitantes evalúan diversos factores como la información que proporcionan los guías, la habilidad para interactuar con el grupo a cargo, el buen manejo del idioma y el carisma. Este último es relevante para los visitantes quienes clasifican a los guías como: divertido, ameno, atento, e incluso apasionado con las explicaciones. La información que proporciona el guía puede ser básica para algunos visitantes si estos tienen conocimientos de arte".
Para Schmilchuk (1996), el cambio de perspectiva en la Museología con respecto al público va desde la "idea del público general indiferenciado a otra de públicos con competencias e intereses diversos o de consumidores efectivos y potenciales como agentes económicos en una relación de mercado, definidos por sus expectativas, necesidades, percepciones y prácticas respecto a un producto; de la función de conservación e investigación a la destreza de comunicación y destreza administrativo-financiera(...) el modelo empresarial permea buena parte del nuevo paradigma".

El $100 \%$ de los visitantes encuestados precisó que, de todas las veces que visitó este museo "nunca" contempló a los Guías de Turismo usar algún equipamiento tecnológico. La logística o equipos que usan los Guías de Turismo son tan variados y siempre están en función de las condiciones geográficas en donde se realiza la operación turística, pero en el caso particular, este museo ofreció dentro de su infraestructura amplias salas de exposición con muy buena acústica, iluminación, amplios pasadizos y también lugares muy reducidos como las catacumbas, las mismas que por su arquitectura dificultó que el Guía de Turismo pueda observar a todos sus visitantes a la vez y por consecuencia el mensaje no fue percibido con claridad por los visitante, todo esto debido al volumen desmedido de visitantes que fue asignado al Guía de Turismo por parte de la administración. El uso de un dispositivo que ayude a mejorar la comunicación del Guía de Turismo hacia el visitante es muy importante, especialmente en las Catacumbas, cada vez que se ha de brindar información, lo cual permitirá capturar la atención del visitante de mejor manera, superando muchas barreras de la comunicación. Este resultado generado por la presente investigación no coincide con la 
tesis de (Martinez, 2017) quien sustenta que "Se observó que, no todos cuentan con micrófonos o alguna herramienta que facilite a los turistas recibir mejor la información, esto es en el caso de grupos grandes y en grupos pequeños de 5 a 10 personas, existen guías los cuales el volumen de su voz no es alta y clara”.

El $14 \%$ de la muestra precisó que su requerimiento "siempre" se atendió, mientras que el $49 \%$ asintió que "a veces" y el $37 \%$ manifestó que "nunca". Los requerimientos de los visitantes del Museo del Convento de San Francisco no fue atendido de la manera esperada, un caso que nos llamó a la reflexión fue el número excesivo de visitantes que se le asignó a algunos Guías de Turismo, se trató de un día en el cual acuden muchos visitantes al museo, durante esta actividad se constató que los visitantes iban abandonando el grupo durante el recorrido, debido a que el Guía de Turismo no se abasteció para atender a un grupo cercano a los cuarenta visitantes, definitivamente todo hizo indicar que este recorrido fue perdiendo interés para los visitantes. Otro caso que nos llamó la atención fue en la sala de espera, en la cual se pudo constatar que, a los visitantes no se les permitió hacer uso de los servicios higiénicos mientras esperaban su turno para iniciar el recorrido por las instalaciones del museo. Esta situación demostró un despropósito hacia los requerimientos de los visitantes, la gestión del museo en vista de una mejora continua puede hacer esfuerzos para coincidir con (Olvera \& Scherer, 2009) quienes precisan que "Calidad significa tratar y buscar siempre satisfacer las necesidades y superar las expectativas de cada uno de nuestros clientes a través de un servicio honesto y profesional, sin importar los costos que esto implique. Cubrir los requisitos mínimos e ir más allá de lo esperado, buscar la mejora continua y la satisfacción total del cliente".

El $60 \%$ de la muestra precisó que el Guía de Turismo "siempre" demostró tener ética profesional, mientras que el $31 \%$ asintió que "a veces" y el $9 \%$ manifestó que "nunca". Definitivamente esta situación se tiene que mejorar y la administración del museo debió asumir alguna medida al respecto, se logró constatar durante una visita en la cual el Guía de Turismo a cargo de nuestro grupo nos informó que podíamos tomar las fotografías que consideremos conveniente de manera muy discreta, pero también nos comunicó que debemos tener cuidado de que algún vigía no nos encuentre infragantes para evitar algún tipo de controversia. Definitivamente hay una norma dispuesta por la administración del museo, que precisa la prohibición de hacer cualquier tipo de toma fotográfica o fílmica, para salvaguardar la integridad de las colecciones de este museo. Ante toda esta situación es importante precisar a los Guías de Turismo, que es de vital importancia comprender e interiorizar el significado de la ética profesional, de tal manera que logremos coincidir con (Ibarra, 2005) quien sustenta en su investigación que "La ética profesional es la expresión de una conciencia moral que posibilita el logro del bienestar social y contribuye a la realización plena del profesionista. Esto es así porque esta ética recupera y antepone a cualquier otro interés, el sentido social de la profesión que consiste en proporcionar a la sociedad los bienes y servicios que requiere para satisfacer sus necesidades. Asimismo, la ética profesional como toma de conciencia moral, permite que el profesionista asuma el compromiso y la responsabilidad de contribuir a través de su práctica profesional a mejorar y elevar las condiciones de vida de una sociedad. En el ejercicio de esa responsabilidad, 
el profesionista encuentra el camino para su realización porque las aportaciones que hace a la sociedad implican el desarrollo pleno de sus capacidades profesionales, la búsqueda y el logro de la excelencia y de la calidad en la prestación de bienes y servicios. En este ámbito, la ética contribuye a mejorar la condición profesional y humana de la persona".

El $100 \%$ de la muestra manifestó que "Nunca" recibió una atención personalizada de parte del museo, en definitiva, se trata de una situación bastante preocupante. Al parecer todo indicó que la falta de atención personalizada que brindó este museo tuvo mucha relación con la manera en que se asignó el número de visitantes por cada Guía de Turismo. En temporadas altas es posible contemplar a un Guía de Turismo conduciendo grupos conformados por treinta o cuarenta visitantes y en temporadas bajas se ha podido contemplar que los grupos están conformados entre quince o veinte visitantes. Esta situación se comprobó durante varias visitas que se realizó.

Esta situación es abordada también por Falk y Dierking (1992) quienes plantean que cada persona establece su propia "agenda de visita" y que esta es la que dirigirá el comportamiento de la persona durante su experiencia en el museo.

La falta de atención personalizada más resaltante a nuestro criterio se contempló en las Catacumbas en la cual una visitante manifestó signos de claustrofobia, pero el grupo fue tan numeroso que el Guía de turismo nunca se percató que una integrante de su grupo entró en una crisis de nervios, producto de los espacios reducidos. Algo que es muy cierto, es que el Guía de Turismo antes de ingresar con sus respectivos grupos de visitantes a las Catacumbas, preguntó si alguien sufre de claustrofobia. Pero también es cierto que hay personas que ignoran que sufren de claustrofobia. Definitivamente este impase no se hubiese presentado si el grupo de visitantes hubiese estado conformado en función a la capacidad de atención que puede solventar el Guía de Turismo. Para mejorar esta situación la administración del museo debió hacer una mejor gestión de los grupos de visitantes para así coincidir con lo que precisa (CALTUR, 2007) "La atención al turista es también un medio para mejorar la calidad del servicio. No olvidemos que son ellos los gestores de las normas de calidad, gracias a sus sugerencias y necesidades. Es pues, en la labor del guiado que nos encontramos con diferentes tipos de turistas, y es mediante el conocimiento de sus necesidades y el conocimiento del turista mismo que se logra una atención personalizada, asumiendo un comportamiento determinado".

\section{CONCLUSIONES}

- Se identificó que la mayoría de los visitantes del Museo del convento de San Francisco perciben que los Guías de Turismo no realizan su trabajo con mucho entusiasmo siendo una necesidad la elaboración de guiones turísticos en función a sus públicos.

- Una barrera que dificulta el entendimiento de la explicación realizada por el Guía de Turismo es la conducción en las Catacumbas que en algunas ocasiones por el excesivo número de visitantes sumado a ello el espacio reducido que no permite una adecuada ubicación de los visitantes o el débil timbre de voz que suelen tener algunos Guías es necesario utilizar micrófonos portátiles.

- Debido a la percepción de no contar con un servicio de calidad en el Museo del convento de San Francisco es necesario la elaboración de un manual de procedimientos administrativos y de los recursos humanos, el cual debe plantear nuevos procesos 
o mejorar los ya existentes para la prestación del servicio y así poder satisfacer los requerimientos solicitados por el visitante.

- El aforo de atención de cada Guía de Turismo no debe superar la cantidad de 15 visitantes, asimismo es importante que en las Catacumbas se disponga de la presencia de algún vigía o Guía de Turismo asistente para que pueda servir de apoyo en caso se presente una contingencia con visitante alguno.

\section{REFERENCIAS BIBLIOGRÁFICAS}

CALTUR. (2007). Manual de buenas prácticas, guias de turismo y operación turística. Lima, Perú: MINCETUR.

Falk, J. H. y Dierking, L. D. (1992). The museum experience. Washington; D.C.: Whalesback Books.

Farfán, C. (2015). La Gestión Del Servicio Como Propuesta De Mejora Para La Satisfacción De Clientes Caso: Museo San Francisco De Lima. Lima, Perú: UNMSM.

Gran Enciclopedia del Perú. (1998). Lima. Barcelona, España: Lexus.

Hein, G. (2012). El museo constructivista. Recuperado el 11 de Marzo de 2019, de CECA: http://www.banrep.

Ibarra, G. (2005). Ética y formación profesional integral. México: Reencuentro.

Martinez, Y. (2017). Calidad De Servicio De Los Guías Oficiales De Turismo Desde La Perspectiva Del Turista Nacional,Centro Histórico De Lima 2017. Lima, Perú: Universidad César Vallejo.
Olvera, I. y Scherer, A. (2009). El cliente y la calidad en el servicio / Quality Customer Service. Trillas.

Schmilchuk, G. (1996). Venturas y desventuras de los estudios de público. Cuicuilco. 